\section{LA COMUNIDAD}

Álvaro Oyarzún | Artista visual, Galería AFA

Pintor y artista visual, realizó cursos de arte en el Instituto de Arte Contemporáneo de Santiago y en la Pontificia Universidad Católica de Chile, pero se define como artista autodidacta. Permaneció por más de diez años en París, en donde recibió la Beca del Fond Regional d'Art Contemporain (1994) y fue premiado en el Concurso Internacional de Pintura de Vitry-sur Seine (1995). Su obra ha sido expuesta en EE.UU. y Chile y forma parte de las colecciones del Blanton Museum en Austin y del Museo de Arte Contemporáneo de Castilla y León MUSAC en España, así como de colecciones privadas en Chile y España. Actualmente vive y trabaja en Santiago. Oyarzún. Se trata de 428 dibujos a tinta sobre piezas de papel de pequeño formato y diferentes colores, montados de modo de mosaico en un intento de vincular el dibujo con la abstracción geométrica.

El conjunto se presenta como una realidad caleidoscópica y una sola narración a la vez: a la distancia, aparece como una pintura desfragmentada que, en proximidad, se transforma en una sumatoria de pequeños relatos que pueden ser leídos visual o textualmente.

La comunidad es una pintura y a la vez un mapa visual; un atlas de escenas y diálogos que debe ser navegado con atención y sentido del humor.
Bibliografía sugerida

AA.VV. 3 Perspectives. Eugenio Espinoza, Alvaro Oyarzún, José Alejandro Restrepo. Cisneros Fontanals Art Foundation, Miami, 2007.

CAPITANIE, Jean Paul y Julien GUERRIER. L'espace culturel Louis Vuitton: Territoires de création contemporaine. Actes Sud Editions, París, 2011.

RICHARD, Nelly y Justo MELLADO. Cirugía Plástica: Konzepte Zeitgenössischer Kunst Chile 19801989. Neue Gesellschaft für Bildende Kunst, Berlín, 1989.

http://www.galeriaafa.com

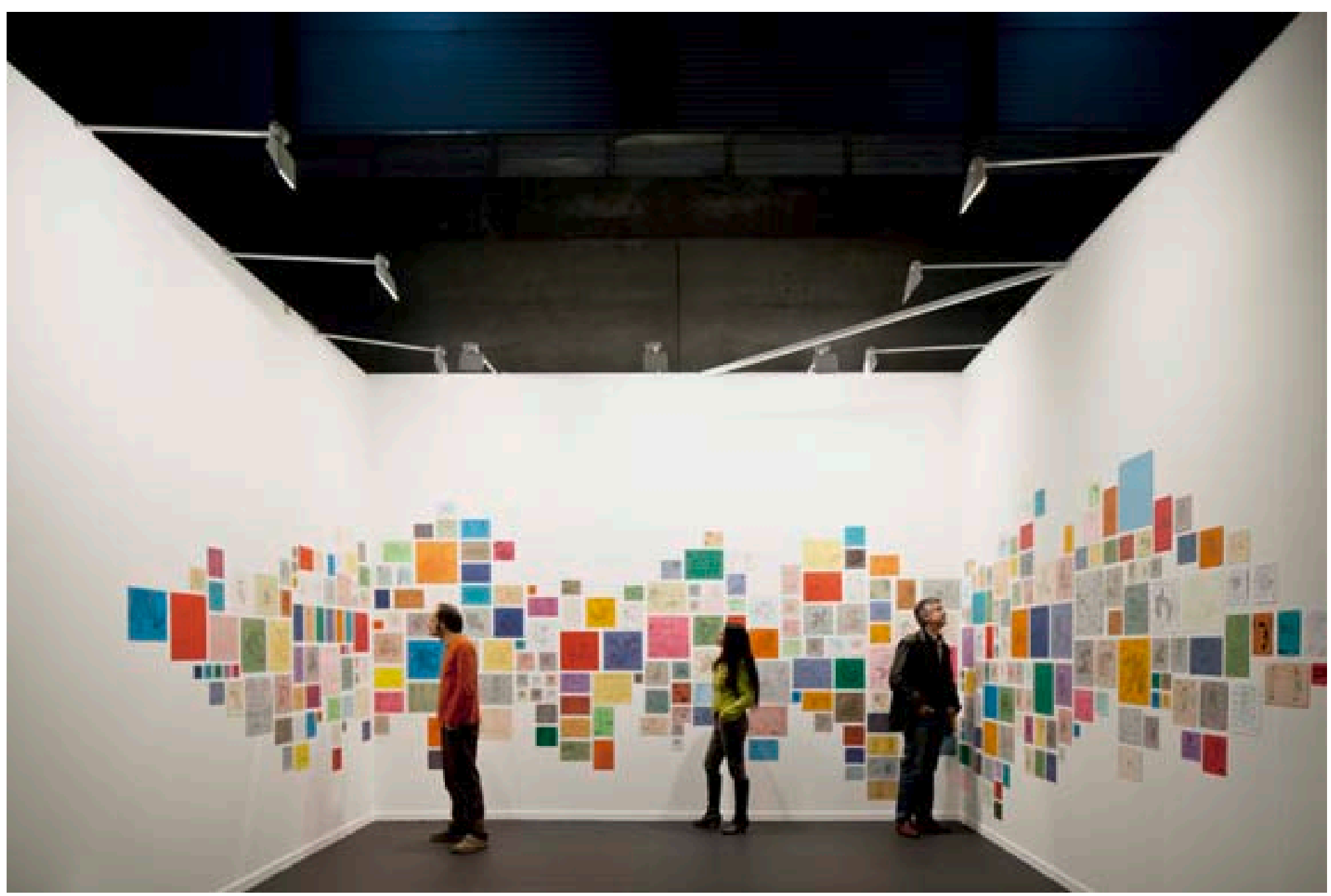




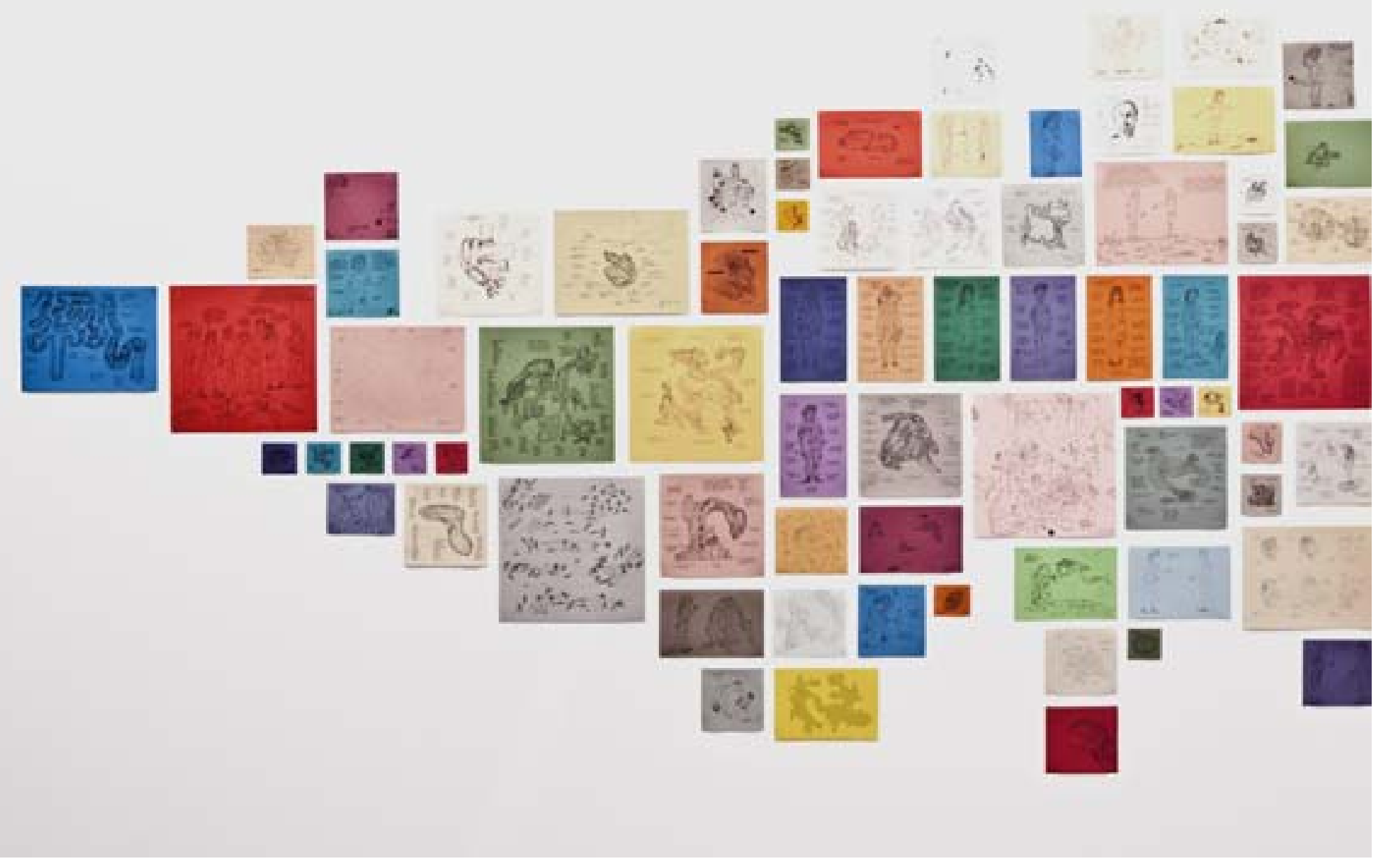




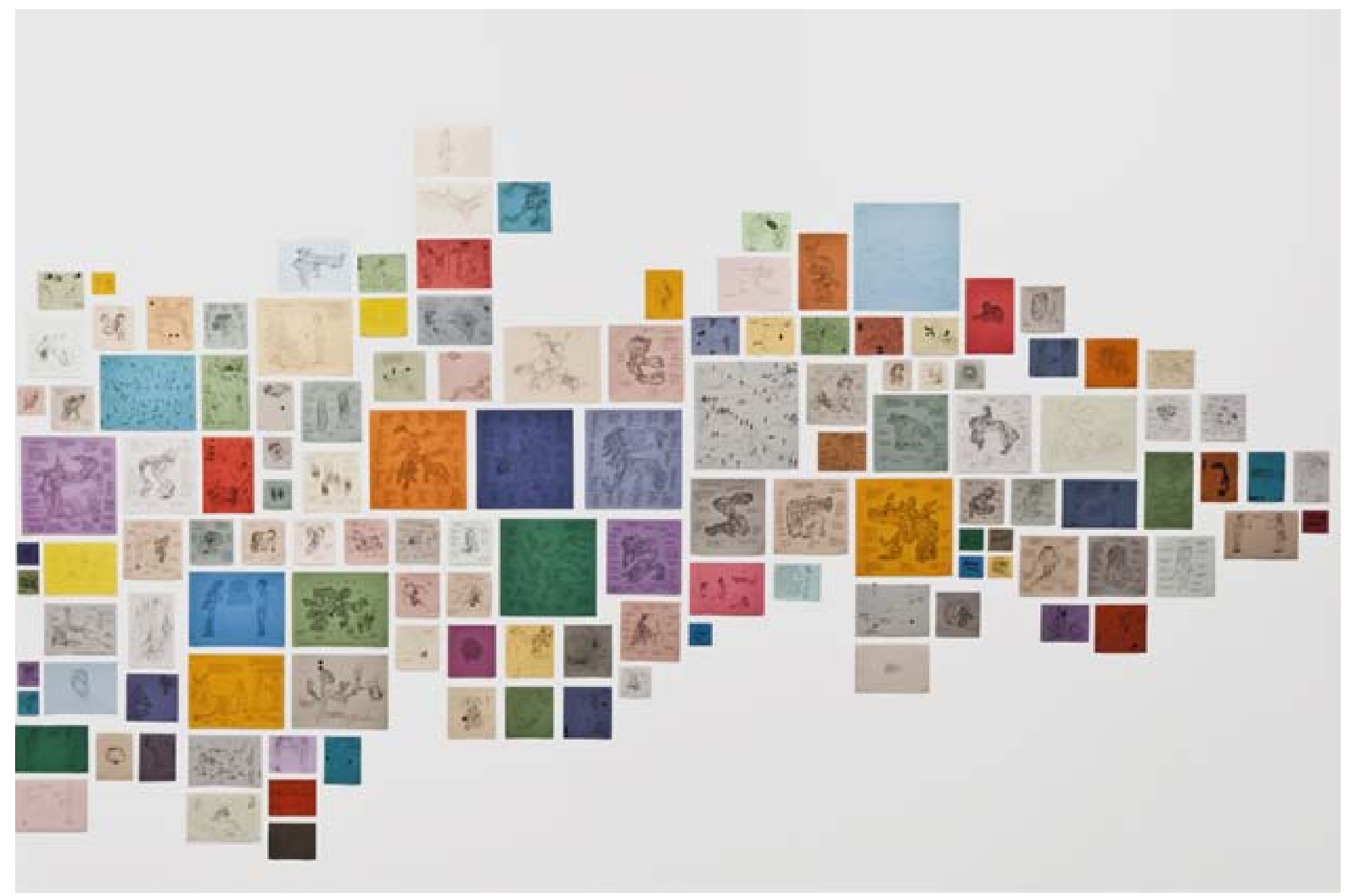

